\title{
FACTORS AFFECTING BOTANIC PARK VISITATION:A CASE OF SAIGON ZOO AND BOTANICAL GARDENS
}

\author{
Nguyen Hoang Sinh, Ho Chi Minh City Open University
}

\begin{abstract}
Increasing number of people is becoming more active in park visitation and ecotourism. It is therefore important for park managers to understand future trends in visitor use of parks. This research paper is designed to understand the motivational factors or the psychological reasons why people visit parks in order to create the suitable marketing campaign to target them. As well as that, it discovers the facilities and attractions of parks that are most important to the visitors, so that the management of parts can disburse its resources in the best areas to achieve maximum output and return. Furthermore, the research aims to find the best communication channels for tourism destinations to reach its target audience so that its marketing expenditure can yield the maximum return. A survey with 228 participants who have visited Saigon Zoo and Botanical Gardens in the last 12 months was conducted. The research result will be critical for the adaptive management of parks and for building the capacity to manage changes and shifts in visitation patterns and park usage. Saigon Zoo and Botanical Gardens would take advantage of this trend and secure a substantial proportion of the new park visitors.
\end{abstract}

Keywords: 'push and pull' factors, park visitation, botanic park, ecotourism.

\section{INTRODUCTION}

Parks are major destinations for the increasingly popular activities of naturebased leisure travel and ecotourism (Butler \& Boyd, 2000, cited in Galloway, 2002). People visit parks for a variety of reasons, including taking rests, escaping from everyday routines, spending time with friends and family and appreciating what nature has to offer. Parks enhance the quality of life of communities and help preserve priceless historic, cultural, and recreational resources for local residents and tourists (The Arizona Hospitality Research \& Resource Center, 2002).

Parks which act as tourism and recreational areas are means of providing income generating opportunities that are complementary to nature conservation as well as the welfare of the local population. Hence, the existence of these parks is important to the community (Hearn \& Santos, 2005). According to the Australian Bureau of Statistics (2006), increasingly numbers of people are becoming aware of the need to protect the environment and are embracing 'ecotourism'. The Ecotourism Society (cited in Wood, 1998) defines ecotourism as responsible travel to natural areas that conserves the environment.

Saigon Zoo and Botanical Gardens (SZBG), a cultural place of Ho Chi Minh City, has a diversity of fauna and flora which aims to conserve animals and plants, especially those of endangered species and educate the public. SZBG is the biggest zoo of Vietnam, and also a 
place for people to visit and study about fauna and flora (Saigon Zoo and Botanical Gardens, n.d.). Visitors not only can study animals and plants, but can also learn how to protect these species. It is an interesting destination that both Vietnamese and foreigners should visit when they come to Ho Chi Minh City.

In order to attract more visitors to parks it must discover and understand the reasons why people visit parks. The objectives of this research are to determine the demographics (including age, sex, education level, marital status and income) of visitors to parks, the main source of information that visitors use to seek information, which demographic group/s is/are the largest segment of customers and to which media they are most exposed, how much more visitors are willing to pay if there is an increase in entrance fees, the 'push factors' or the motivational factors that triggers people to visit parks, the 'pull factors' such as the features, attractions and attributes of the park which draw people to visit, and if their sociodemographics influence these factors. It also is to generate market segments from the target population (based on their motivational factors and pull factors) and group similar 'features/facilities' together so we can promote these services together in the advertising to create a better impact.

The research result will be useful for the management of parks for the following reasons: The analysis of the differences in the push and pull factor domains for different demographic groups will help the managers in understanding these differences in order to improve visitor satisfaction and encourage repeat visitation. Information relevant to marketing could be used to design ad campaigns to attract more members of each demographic group. Tourism researchers, marketing practitioners and fieldworkers can use this research as a reference for subjects including park visitation, botanic parks, ecotourism, and outdoor recreational areas.

\section{Conceptual framework}

\section{Secondary Research}

There have been several studies which discuss the psychographic reasons as to why people visit parks. These primarily deal with push and pull factors that influence people's decisions and/ or motivations when visiting a park. They help to understand some of the key elements in designing conceptual frameworks regarding demographics and frequency scales as Kim, Lee \& Klenosky (2003) stated 'the push-pull framework provides a useful approach for examining the motivations underlying tourist and visitation behaviour' (p.179-180).

The definition of push and pull factors have been explained by Galloway (2002). Push factors (reasons for visiting): internal forces that push people to visit, the motivational reasons for visiting a particular destination. Pull factors (how well the park performs, the attractiveness of a travel destination): external forces of the destination that pull people to choose that particular place.

The relative importance of the motivational forces has been found to vary as a function of visitors' sociodemographic characteristics (Kim, Lee \& Klenosky, 2003). The segmentation of these factors can guide the management team in the design of advertising messages, and the choice of activities, facilities, and information for different groups of park visitors.

Parks are important assets to the community, they provide visitors the opportunity to explore and experience unique natural, historical and cultural resources. Kim, Lee and Klenosky 
(2003) have stated that parks provide a natural setting to relax, be adventurous and explore, and contribute greatly to the communities' wellbeing both directly and indirectly. The following values were identified: (a) Natural values: parks encompass some of the most scenic and biologically diverse lands in the region; (b) Cultural values: parks conserve and provide public access to a wide diversity of experiences. Parks also protect landscapes and places of great importance to local communities; (c) Economic values: parks are being increasingly recognized for their potential to encourage economic activity in rural and regional areas. Expenditure by people visiting parks and expenditure on park management encourages economic activity and generates employment; and (d) Social values: parks provide a range of social benefits, including recreation, tourism, education and social interaction between groups, families and others. They also support community wellbeing and provide opportunities for improving general community health through outdoor recreation. Parks also provide examples to the community of natural landscapes and ecological systems.

Some explains that people visit parks primarily to enjoy and experience nature (The NSW Department of Environment and Conservation, 2006). Other reasons include rest, relaxation or respite from everyday routine, tranquility, recreation, sightseeing and socializing. The most important factors visitors perceive as affecting the quality of their experiences are the 'natural features' and the 'unspoilt nature' of park environments.

Visitors expect a range of settings, experiences, facilities and services reflecting wide-ranging outdoor interests. Some want solitude or adventure with few facilities or constraints. Some would like to enjoy the bush but expect basic facilities or simply want a nice outdoor setting for a picnic. Others may be looking for a cultural experience, whether it's learning about the unique cultural values of parks or meeting and participating in cultural traditions.

\section{Exploratory Research}

- Focus Group. A focus group consists of 9 participants who are comprised of 4 males and 5 females (4 undergraduate students, 4 postgraduate students, 1 non-student; 6 single, 3 married; all between the ages of 20-30). The general outputs of the focus group discussion are listed: source of information ( $\mathrm{TV}$, radio, magazines, newspaper, the Internet, leaflets and brochures, billboards, and word of mouth); their opinions of the push/pull factors; the facilities they view as important to a botanic park; the possible residential statuses of park visitors.

- In-Depth Interviews. In-depth interviews were conducted with 44 year old, male, married with children; 44 year old, female, married with children; 29 year old, male, married without children; 53 year old, male, married with children and grandchildren; 48 year old, female, married with children. A series of questions regarding parks and recreational areas as well as specific subject matters concerning SZBG were discussed between the interviewer and each of the respondents. The interviewees help in contributing ideas as to what should be included in the conceptual framework such as what they like and dislike about SZBG, and how can the attractions and facilities of SZBG be improved.

These interviews generated further source of information for parks and recreational areas, which includes the yellow pages, white pages and road directories. As well as that, these people have a different opinion of the facilities that important to a recreational area as 
compared to the focus group discussion. For example, they rated tranquil rest areas, convenient (easy to locate and access) restrooms, cultural and historic resources more highly compared to the participants in the focus group.
From the secondary and exploratory research and within the context of SZBG, the following conceptual framework is constructed.

\section{Figure 1. The Conceptual Framework}

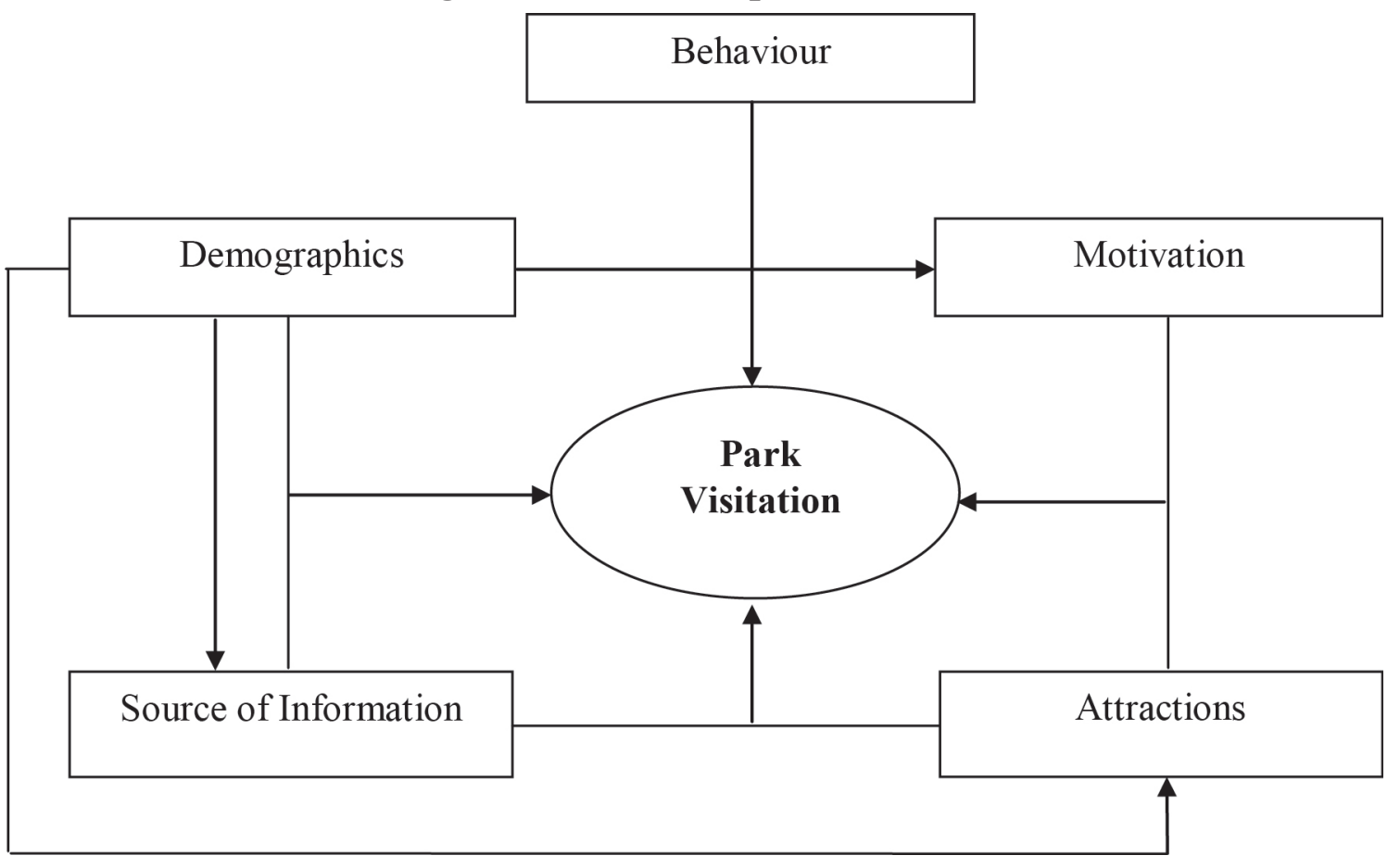

As shown in Figure 1, people visiting a particular destination is triggered by reasons including the motivational forces (push factors) and external forces/attractions of park (pull factors). Behaviour, demographics and source of information are also factors influencing park visitation.

\section{Methodology}

The research instrument used for this study is a two page self-administered questionnaire. The basis of the research is carried out using the scale items used by
Galloway (2002) and Kim, Lee \& Klenosky (2003). Many of the elements in the push and pull factors are used as the domains of proposed conceptual framework as well as research questionnaire. This is because the relative importance of the motivational forces (push and pull factors) has been found to vary as a function of visitors' socio-demographic groups (Kim, Lee \& Klenosky, 2003). Similarly to Galloway's research, the fundamental analysis of this research will focus on the relationships between the visitors' demographics and their motivational reasons for visiting parks. 
Table 1. Scale Items of the Conceptual Framework

\begin{tabular}{|c|c|}
\hline Factors & Items of Measurement \\
\hline Motivation (Push factors) & $\begin{array}{l}\text { To have enjoyable time with family } \\
\text { To appreciate historic/cultural resources } \\
\text { To enjoy natural resources } \\
\text { To enhance health } \\
\text { To take a rest } \\
\text { To get away from everyday life } \\
\text { To avoid hot weather } \\
\text { To fulfil curiosity } \\
\text { To have a time for natural study }\end{array}$ \\
\hline Attractions (Pull factors) & $\begin{array}{l}\text { Convenient parking lots are available } \\
\text { There are tranquil rest areas } \\
\text { Tourist information is well-organised } \\
\text { Restrooms are conveniently located } \\
\text { There are adequate BBQ facilities and drinking stands } \\
\text { Restaurants/cafés are of good quality } \\
\text { There are cultural and historic resources } \\
\text { It is a well-conserved environment } \\
\text { The park is easy to access } \\
\text { It is an appropriate area for children's study on natural resources } \\
\text { There are beautiful natural resources } \\
\text { There are rare flora and fauna (plants and animals) }\end{array}$ \\
\hline Source of Information & $\begin{array}{l}\text { Television } \\
\text { Radio } \\
\text { Magazines } \\
\text { Newspaper } \\
\text { The Internet (World Wide Web) } \\
\text { Leaflets, pamphlets and brochures } \\
\text { Directories (Yellow/White pages) } \\
\text { Billboards and outdoor ads } \\
\text { Word of mouth }\end{array}$ \\
\hline Behaviour & $\begin{array}{l}\text { Number of visits } \\
\text { Price sensitivity } \\
\text { Likelihood of coming back } \\
\text { Likelihood of becoming a member } \\
\text { Likelihood of recommending the park }\end{array}$ \\
\hline Demographics & $\begin{array}{l}\text { Age } \\
\text { Sex } \\
\text { Education } \\
\text { Marital status } \\
\text { Income } \\
\text { Cultural background } \\
\text { Local/International }\end{array}$ \\
\hline
\end{tabular}

After the completion of draft questionnaire, pretesting is used to minimise the errors and any potential flaws to the questions and/or the design of the survey (Burns \& Bush 2003). There are several errors which were spotted and amended during pretesting, these included: missing grid lines and inconsistency of border lines; spelling errors; inconsistency and overlap of annual income divisions; added 'not completed high school' for education status. 
The criterion set for survey respondents is anyone who has visited SZBG in the last 12 months, which transpired as the basis of study target population.

\section{Results and discussion}

In this research, 228 completed questionnaires are collected from the target population. A statistical description of the sample and demographics is shown in Table 2.

Table 2. Sample Characteristics

\begin{tabular}{|c|c|c|c|c|c|}
\hline Age & $\%$ & Marital status & $\%$ & Much more pay (VND) & $\%$ \\
\hline $20 \&$ under & 20.6 & Single & 27.0 & 10,000 or less & 33.9 \\
\hline $21-30$ & 35.1 & In a relationship & 26.4 & 20,000 & 37.0 \\
\hline $31-40$ & 15.4 & Married & 36.6 & 30,000 & 12.8 \\
\hline $41-50$ & 15.8 & Annual income (Mil.) & $\%$ & 40,000 & 5.3 \\
\hline $51-60$ & 7.5 & Less than 3.5 & 51.1 & 50,000 & 10.6 \\
\hline $61 \&$ over & 5.7 & $3.6-5.0$ & 22.0 & 60,000 or more & 0.4 \\
\hline Sex & $\%$ & $5.1-6.5$ & 13.9 & Educational qualification & $\%$ \\
\hline Male & 52.6 & $6.6-8.0$ & 6.7 & Not completed high school & 29.1 \\
\hline \multirow[t]{2}{*}{ Female } & 47.4 & $8.1-9.5$ & 3.6 & Completed high school & 67.8 \\
\hline & & More than 9.5 & 2.7 & Completed graduate degree & 3.1 \\
\hline
\end{tabular}

The largest portion of the respondents is aged between 21-30 years old (35.1\%). The data also shows that $55.7 \%$ of respondents are below 31 years old. This means that the information collected may be skewed and inaccurate due to the disproportionate representation of the population. The percentages of male and female respondents are quite even, each making up approximately half of the total sample size. There are only 5.2\% more male respondents than female respondents. There is an almost equal representation of each marital/relationship status group. $70.9 \%$ of the respondents have at least completed high school, and almost 30\% have not completed high school. $50 \%$ of the respondents earn less than VND 3.5 million annually, which suggests a large portion of the respondents are probably unemployed, work part time, retired or are students. Only $6.3 \%$ of the respondents earn more than VND 8.0 million in annual income. This means that there are very few high income earners who responded to the survey.

- Price sensitivity. Over $70 \%$ of the respondents are not willing to pay more than VND 20,000 to an increase to the entrance fee. The mean is VND 20,230 which means that the average respondent (in terms of mean) is willing to pay approximately VND 20,230 extra if there was an increase in entrance fees. However, due to the ambiguity of the answers 'VND 10,000 or less', and 'VND 60,000 or more', the mean of VND 20,230 cannot be justified as the average.

- Source of information. It is important to find out what sources of information visitors to SZBG use when they want to obtain information about parks and recreational areas so the SZBG can utilise the best media channels to reach their market. 
Table 3. Source of Information

\begin{tabular}{|l|c|c|c|}
\hline Source & N & Mean & S.Deviation \\
\hline Television & 226 & 3.13 & 1.651 \\
\hline Radio & 224 & 2.83 & 1.593 \\
\hline Magazine & 227 & 3.05 & 1.576 \\
\hline Newspaper & 227 & 3.30 & 1.588 \\
\hline Internet & 224 & 3.53 & 1.853 \\
\hline Leaflets and brochures & 224 & 3.48 & 1.596 \\
\hline Directories & 225 & 2.97 & 1.612 \\
\hline Billboards & 225 & 3.11 & 1.840 \\
\hline Word of mouth & 227 & 5.06 & 1.611 \\
\hline
\end{tabular}

The higher the mean, the more frequent the information source is used. As the above table suggests, 'word of mouth' is the most sourced information, followed by the Internet and leaflets/brochures. Therefore, people usually visit parks based on recommendations/referrals from friends and family rather than from mass media marketing efforts such as radio, magazines, and newspapers. Information is least sourced from the radio.

- Annual income and education with price sensitivity. The significance level is more than 0.05 (Sig.=0.508); therefore, there is no relationship between 'annual income' and 'how much they're willing to pay'. The significance level of the Pearson Chi-Square test is below 0.05 (0.004), hence we can be confident enough to infer that there is a relationship between 'highest qualification' and 'how much more willing to pay'. Furthermore, from the Grosstabulation it can see that the higher the educational level, the more they are willing to pay for an increase in entrance fees. The lower the educational level, the lesser they are willing to pay.

- Attractions with visitation. The three most important facilities/attractions in general are 'beautiful natural resources' $(M=5.48)$, 'well-conserved environment'
(5.39), and 'tranquil rest areas' (5.29). The results suggest that older people (51 and above) regard these facilities/attractions more importantly as compared to younger people (below 50). Younger people tend to regard 'BBQ facilities', 'well-conserved environment', 'convenient parking lots', 'beautiful natural resources' as more important than other factors.

'Convenient parking lots' $(M=5.34)$, 'tranquil rest areas' (5.63), 'tourist information' (4.61), 'convenient rest rooms' (4.72), 'good quality café' (4.98), 'well conserved environment' (5.69), 'accessibility' (5.10), 'children's study' (4.95), beautiful natural resources' (5.95), and 'rare fauna and flora' (4.95) all seem to be more important to married people than singles. However, singles tend to regard 'BBQ facilities' (5.19) more importantly than married people.

- Social-demographics with source of information. For 'use of leaflets \& brochures' (Sig. $=0.007)$ and 'use of billboards' (0.019), the corresponding significance level for the T-test is less than 0.05 indicating that there is a significant difference between how males and females rate these sources of information. As the Group Statistics table suggests, females tend to rely more on the use of 'leaflets and 
brochures' and 'billboards' when obtaining information about parks and recreational areas as compared to males.

It notes that 'use of directories' is the only variable that has a Sig. $=0.00$, indicating that there is a significant difference between the use of directories by the different age groups. There is a difference between those who are ' 20 \& under' compared to ' $31-40$ year olds'. As the means plot shows, 31 to 40 year olds rely on the use of directories more than 20 year olds and under. The statistics also shows differences between other age groups, however, the significance level for all others are more than 0.05 . Hence, no conclusions can be drawn from those.

The statistics show that 'use of billboards' is the only variable that has a Sig. $=0.02$, indicating that there is a significant difference between the use of billboards by people with different educational qualifications. As the Multiple Comparisons table suggests (all have a Sig.>0.05), there is no significant difference between any of the educational qualification groups and their use of billboards.

The results show that "use of magazines", "use of newspaper", "use of leaflets and brochures', 'use of directories', and 'use of billboards' all have a Sig. $<0.05$, indicating that there is a significant difference between the use of these sources of information by those who are single, in a relationship and married. As the Multiple Comparisons table suggests, singles and married people differs in their use of 'magazines', 'newspapers', 'leaflets and brochures', 'directories' and 'billboards'. There is no significant difference between those in a relationship as compared to those who are single or married.

- Motivation with visitation. As the statistics suggest, people in different age groups differs in how they rate 'enjoy time with family' (Sig. $=0.000)$, 'appreciate cultural resources' $(0.005)$, 'enjoy natural resources' (0.016), and 'enhance health' (0.032). 'Enjoy time with family' is least important to visitors under 20 years old, while those above 30 years of age rate it as lot more important. 'Appreciating cultural resources' are least important to 21 to 30 years old, and most important to those more than 50 years old. People who are between 31 to 40 years old and those who are over 61 rate 'enjoy natural resources' the most important. Visitors tend to rate 'enhance health' more important as they get older, and less important as they reach above 50 years of age.

The results show no significant differences in how males and females rate the importance of all push factors (all have a Sig.>0.05). For 'enjoy time with family' (Sig. =0.016), 'avoid hot weather' (0.037) and 'natural study' (0.029), the corresponding significance level for the T-test is less than 0.05 indicating that there is a significant difference between how married and unmarried people rate these factors. The results suggest unmarried visitors regard 'enjoy time with family' $(M=5.55)$ and 'have time for natural study' (3.53) more importantly compared to married visitors (5.06, 3.01 respectively). Married people seem to view 'avoiding hot weather' (4.04) more important than unmarried people (3.50).

- Factor Analysis. Factor analysis has simplified the 9 variables of "motivational factors" to be represented by 3 factors. The first group of variables includes 'get away from everyday life', 'take a rest', 'enhance health', and 'enjoy time with family'. The second group includes 'appreciate cultural resources' and 'enjoy natural resources'. The third group includes 'have time for natural study', 'fulfill curiosity' and 'avoid hot weather'. These should become 
the basis of future marketing segments. Factor analysis has also simplified the 12 variables of "facilities and attractions" to be represented by 3 factors. The first group of variables includes 'children's study', 'rare fauna and flora', 'easy to access', and 'cultural and historic resources'. The second group includes 'convenient rest rooms', 'tourist information', 'adequate BBQ facilities', and 'good quality café'. The final group includes 'tranquil rest areas', 'beautiful natural resources', 'wellconserved environment' and 'convenient parking lots'. If SZBG is to market its attractions and facilities, they should provide these three groups of factors as packages.

Most of the correlation ( $r$ ) are relatively weak except for 'rare fauna and flora' and 'children's study', which yielded a 0.597 correction, as well as 'tourism information' and 'convenient rest rooms' which yielded a 0.577 correlation. These correlations represent a moderately high positive correction. That means people who care about 'rare fauna and flora' also cares for 'children's study'. Those who regard 'tourism information' as important also want 'convenient rest rooms'. Other correlations are all positive, but relatively weak. Hence, these variables should be marketed together when possible.

\section{CONCLUSION}

The fundamental purpose of this research is to seek factors affecting park visitation to attract more visitors through understanding the motivational factors or the psychological reasons why people visit parks in order to create the suitable marketing campaign to target them. As well as that, the paper aims to discover the facilities and attractions of park that are most important to visitors, so that the management of parks can disburse its resources in the best areas to achieve maximum output and return.
The research also aims to find the relationships between the sociodemographics of visitors and their motivational reasons for visiting a park as well as the importance of the facilities and features of park to each demographic group. Furthermore, the objective of the research is to find which sources of information are used most frequently by park visitors so that the management of parks can utilise these media channels to communicate and market the features of park to its target population.

The research found that people very seldom seek information regarding parks and recreational areas from mass media channels such as $\mathrm{TV}$, radio, magazines, and newspapers. The most effective communication marketing tool is 'word of mouth', which the management has little control, because it's usually engaged and executed by the visitors themselves. Although it is difficult for a tourism destination such as the SZBG to use 'word of mouth' as its key marketing strategy, the park management should encourage its patrons to encourage and recommend friends and family to visit the park. For example, instead of injecting a large sum of revenue into advertising, the park should give incentives for people to come back in the future and bring their friends and family. This can be done by giving vouchers (refreshment vouchers or single entry coupons) that cannot be used on the day (but expires within a month or two) to visitors leaving the park. Single entry coupons are useful because visitors seldom come alone.

This study shows that the Internet has been used more frequently as a source of information for parks and recreational areas as compared to traditional media (such as TV, radio, newspapers and magazines). Although SZBG already has a website and is taking advantage of the web, 
it can be further developed to maximise its effectiveness by allowing online bookings for personal, corporate events/celebrations as well as on-line forums to encourage feedback and suggestions.

If the management wants to raise revenue through increasing entry fees in the future, they should keep in mind that over $70 \%$ of the respondents are not willing to pay more than VND 20,000 to an increase in entrance fee. Slight increases over time will always be better than a single dramatic increase in the entrance fee because people tend to not notice insignificant changes.

There are no major 'standouts' in the socio-demographic groups that requires particular attention because most of these groupings are quite evenly dispersed. Therefore, the park should aim its campaigns at the whole target population. There are however some psychographical groups which the park can specifically target. For example, people who visit parks to get away from everyday life also want to take a rest, enhance health, and enjoy time with their family. These benefits of the park can be bundled into a single marketing campaign. Another marketing bundle can be created for those who appreciate cultural resources as well as enjoy natural resources. The third group includes those who seek to have time for natural study, fulfill curiosity and avoid hot weather.

If the park wishes to advertise or enhance its attractions and facilities, they should consider grouping 'children's study of natural resources', 'rare flora species', 'easy to access', and 'cultural and historic resources' into one campaign because each of those features have been found to be correlated. While the second should include 'convenient rest rooms', 'tourist information', 'adequate BBQ facilities', and 'good quality café/restaurant'. The final group should include 'tranquil rest areas', 'beautiful natural resources', 'wellconserved environment' and 'convenient parking lots'.

\section{REFERENCES}

The Australian Bureau of Statistics (2004), Environmental Issues: People's Views and Practices, cat. no. 4602.0, ABS, Canberra.

The Arizona Hospitality Research and Resource Center (2002), Economic Impact of State Parks. Retrieved March 15, 2011, from http://www.azcommerce.com/doclib/ PROP/StateparksEIA\%20exec\%20summary.pdf

Bigne, J.E., Andreu, L. and Gnoth J. (2004), 'The Theme Park Experience: An Analysis of Pleasure, Arousal and Satisfaction', Tourism Management, vol. 26, no. n/a, pp. 833-844.

Burns, A. and Bush, R. (2003), Marketing Research, 4th ed, Prentice Hall, New Jersey.

The NSW Department of Environment and Conservation (2006), Living Parks: A Sustainable Visitation Strategy. Retrieved May 10, 2011, from http://nationalparks. nsw.gov.au/PDFs/Living_Parks.pdf

Galloway, G. (2002), 'Psychographic Segment of Park Visitor Markets: Evidence for the Utility of Sensation Seeking', Tourism Management, vol. 23, no. n/a, pp. 581-596.

Hearne, R.R. and Santos, C.A. (2005), 'Tourists and Locals Preferences toward Ecotourism Development in the Maya Biosphere Research, Guatemala', 
Environment, Development and Sustainability, vol. 7, no. 3, p. 303.

Wood, M.E. (1998), 'Meeting the Global Challenge of Community Participation in Ecotourism: Case Studies and Lessons from Ecuador', The Nature Conservancy, Working paper, no. 2, p. 10.

Kim, S.S., Lee, C.K. and Klenosky, D.B. (2003), 'The Influence of Push and Pull Factors at Korean National Parks', Tourism Management, vol. 24, no. 2, pp. 169-180.

Kjeldal, S. (2002), 'Back to Basics: The Sequencing of Inductive and Deductive. Research Methodologies in Fresh Fruit and Vegetable Research', Forum: Qualitative Social Research, vol. 3, no. 3, p. 41.

Saigon Zoo and Botanical Gardens (n.d.), About us. Retrieved May 1, 2012, from http:// www.saigonzoo.net/lang/en. 